\title{
Anthropometric predictors of gestational hypertensive disorders in a remote aboriginal community: a nested case-control study
}

\author{
Maryam Sina*, Wendy Hoy and Zhiqiang Wang
}

\begin{abstract}
Background: Australian Aboriginal women tend to have body shape and pregnancy risk profiles different from other Australian women. This study aims to examine the associations of anthropometric indices with gestational hypertensive disorders (GHD), and to determine the index that can best predict the risk of this condition occurring during pregnancy.

Methods: This is a nested case-control study. Baseline body mass index (BMI), waist circumference (WC), hip circumference $(\mathrm{HC})$, waist-to-hip ratio $(\mathrm{WHR})$ and waist-to-height ratio $(\mathrm{WH}+\mathrm{R})$ were measured as part of a broader health screening program between 1992 and 1995 in a remote Aboriginal community. All subsequent pregnancies among the original participants were identified during 20 year follow-up period through hospital records (up to May 2012). Twenty eight women were diagnosed as having GHD, each of whom were individually matched by age at baseline with five women who were hospitalised for other pregnancy-related conditions and were free from GHD $(n=140)$. The associations of the baseline anthropometric measurements with GHD were assessed using conditional logistic regression.
\end{abstract}

Results: The best predictor of GHD was WC (OR $=1.8 ;(95 \% \mathrm{Cl}, 1.1-2.9)$ for one standard deviation increase in WC), followed by BMI with the corresponding $\mathrm{OR}=1.7$ ( $95 \% \mathrm{Cl}$, 1.1- 2.6). Other measurements, $\mathrm{HC}$, WHR, and WHtR, were also positively associated with GHD, but those associations were not statistically significant.

Conclusions: WC and BMl prior to pregnancy are anthropometric predictors of GHD in Aboriginal women, and WC is the best predictor. These findings imply the importance of early weight control in preventing GHD in Aboriginal women.

Keywords: Gestational hypertensive disorders, BMI, Waist circumference, Aboriginal women

\section{Background}

Body mass index (BMI) is a relatively reliable indicator of body fatness in clinical and epidemiological studies. However, different ethnic groups have different body fat distributions [1-3]. Aboriginal women tend to have larger waist circumferences (WC), waist-to-hip ratios (WHR) and waist-to-height ratios (WHtR) compared to non-Aboriginal Australians [4]. Other anthropometric measurements than BMI can also be important in epidemiologic studies undertaken in Aboriginal people [5-7] due to their unique body

\footnotetext{
* Correspondence: m.sina@uq.edu.au

School of Medicine, University of Queensland, Postal address: Centre for Chronic diseases, Health Sciences Building, Royal Brisbane and Women
} Hospital, Herston, QLD 4029, Australia shapes, with long-legs in proportion to their body height and low sitting height [8].

Gestational hypertensive disorders (GHD) include gestational hypertension, pre-eclampsia and eclampsia. GHD is associated with an increased risk of chronic conditions such as type 2 diabetes mellitus [9]; it may also increase the risk of maternal and infant mortality $[10,11]$. These associations have been also reported in Australian Aborigines and Torres Strait Islanders (TSI) women [12]. A recent study undertaken in north Queensland showed that for every $1 \mathrm{~cm}$ increase in WC before pregnancy the risk of gestational hypertension increased by $4 \%$ [13]. That study also highlighted that for each one unit increase in BMI before pregnancy, the risk of gestational hypertension increased by $9 \%$. 
The impact of obesity on GHD during and before pregnancy has been reported by a number of studies $[14,15]$. However, the associations of different obesity-related measurements prior to pregnancy with GHD have not been systematically assessed. The objective of this study was to assess the associations of different anthropometric measurements with GHD in Aboriginal women.

\section{Methods}

This is a nested case-control study. Cases and the matched-controls were derived from an existing cohort, established from members of one tribal group living remotely in the Northern Territory, Australia. Baseline anthropometric data were collected as part of a broader health screening program from 1992 to 1995 . All participants were followed up to 31 May 2012, during which GHD were identified through hospital records. Two databases, the baseline screening of anthropometric measurements and a hospitalisation database of hypertensive outcomes were merged according to the patients' hospital registration numbers. An informed written consent was obtained from all participants or guardians (for participants who were younger than 18 years old during the baseline measurements). The original baseline data collection was approved by the Aboriginal community and Menzies School of Health Research Ethics Committees. This project was approved by the University of Queensland Ethics Committee.

\section{Measurements}

BMI was calculated as weight $(\mathrm{kg})$ divided by height squared in meters. For participants older than 18 years at baseline, high BMI was defined as $\mathrm{BMI} \geq 25 \mathrm{~kg} / \mathrm{m}^{2}$. High BMI for participants aged less than 18 years at baseline were defined according to the international BMI cut-off points proposed by Cole et al. [16]. Since BMI changes substantially as a child gets older, and no BMI cut-off values have been developed specifically for Aboriginal children, we used the international BMI cut-off values, as used in previous studies of Aboriginal people [17]. The procedures for performing anthropometric measurements of weight, height, WC and hip circumference (HC) have been described in detail elsewhere [7]. Patients with baseline systolic blood pressure $\geq 140 \mathrm{mmHg}$ and/or diastolic blood pressure $\geq 90 \mathrm{mmHg}$ were considered as hypertensive. Pre-existing albuminuria was defined as a baseline urine albumin-to-creatinine ratio at or above the microalbuminuria threshold of $3.4 \mathrm{mg} / \mathrm{mmol}$ [18].

\section{Pregnancy and GHD ascertainment}

Women who became pregnant during the follow-up period were identified through their hospitalisation records according to the International Classification of Disease (ICD) 9 and ICD 10-AM codes, as shown in Table 1. GHD

\begin{tabular}{|c|c|c|}
\hline $\begin{array}{l}\text { Condition of } \\
\text { pregnancy }\end{array}$ & ICD-9 code & ICD-10-AM code \\
\hline $\begin{array}{l}\text { Pregnancies without } \\
\text { hypertension }\end{array}$ & $\begin{array}{c}630-633.9,641-642 \\
643-650,652-669, \text { V22 }\end{array}$ & $\begin{array}{c}\mathrm{Z34,} \text { O20-O29, O32-O48, } \\
\text { O60-O75, O80-085 }\end{array}$ \\
\hline $\begin{array}{l}\text { Pregnancies with } \\
\text { hypertension }\end{array}$ & 642 & $\mathrm{O} 11, \mathrm{O} 13, \mathrm{O} 14, \mathrm{O} 15, \mathrm{O} 16$ \\
\hline
\end{tabular}

related ICD 10 codes were obtained according to ICD 10 codes used in Chen et al.'s study [19]. Women who were pregnant before the baseline measurements were excluded. A total of 173 women experienced pregnancy during the follow-up period. Of them, women with missing BMI data $(n=5)$ were excluded from this study. Of the remaining 168 women, 28 were identified with GHD, which was defined as having any of the following hypertensive conditions: gestational hypertension, preeclampsia, eclampsia, and pre-existing hypertension with superimposed pre-eclampsia-eclampsia. Participants with the missing other baseline measurements (i.e. WHR, HC) were excluded from the specific analysis $(n=61)$. Only the first identified records of GHD and the first identified records of other pregnancy-related conditions were extracted from the hospitalisation data.

\section{Data analysis}

Controls were individually matched to cases according to age at baseline. Continuous variables were tested for normality using skewness/Kurtosis tests. Most of those continuous variables were not significantly different from a normal distribution among cases; however this could be due to the small sample size. Therefore it is inconclusive whether those variables are normally distributed. To evaluate the associations of anthropometric measurements of BMI, WC, HC, WHR and WHtR as continuous variables with GHD, we used the conditional logistic regression method to calculate odds ratios (ORs) corresponding to one standard-deviation (SD) increase in each of those anthropometric measurements. The association between high BMI and GHD was also assessed using conditional logistic regression by calculating ORs and their 95\% confidence intervals (CI). All models were adjusted for age at pregnancy, alcohol drinking and cigarette smoking. The anthropometric measurement with the highest OR value was considered as the best predictor of GHD. All analyses were conducted using Stata 12 [20].

\section{Results}

Baseline characteristics

Table 2 shows the mean values of baseline characteristics in cases and controls. The mean ages at baseline were 17.7 years $(\mathrm{SD}=9.3)$ and 15.3 years $(\mathrm{SD}=8.2)$ in cases and controls, respectively. The mean values of BMI 
Table 2 Patients' baseline characteristics of the cases with gestational hypertension and the controls

\begin{tabular}{lccc}
\hline Characteristics & $\begin{array}{c}\text { G-hypertension } \\
\text { (case) 28 } \\
\text { Mean (SD) }\end{array}$ & $\begin{array}{c}\text { Other pregnant women } \\
\text { (matched-control) 140 }\end{array}$ & $\begin{array}{c}\text { P-value } \\
\text { Mean (SD) }\end{array}$ \\
\hline Age at baseline & $17.7(9.3)$ & $15.3(8.2)$ & 0.16 \\
Age at pregnancy & $24.6(5.8)$ & $22.4(6.2)$ & 0.10 \\
BMl (kg/m²) & $22.4(9.1)$ & $18.8(5.7)$ & $0.007^{*}$ \\
High BMl & $11(39.7 \%)$ & $26(18.5 \%)$ & $0.016^{*}$ \\
$\begin{array}{l}\text { Waist } \\
\text { circumference (cm) }\end{array}$ & $88.5(19.1)$ & $78.6(15.7)$ & $0.013^{*}$ \\
$\begin{array}{l}\text { Hip } \\
\text { circumference (cm) }\end{array}$ & $98.2(18.9)$ & $89.2(16.6)$ & $0.029^{*}$ \\
$\begin{array}{l}\text { Waist-to-hip ratio } \\
\text { Waist-to-height }\end{array}$ & $0.92(0.05)$ & $0.89(0.06)$ & 0.10 \\
ratio & $0.90(0.06)$ & $0.88(0.07)$ & 0.257 \\
$\begin{array}{l}\text { Systolic BP, } \\
\text { mm Hg }\end{array}$ & $109.4(16.1)$ & $104.7(14.2)$ & $0.09^{*}$ \\
$\begin{array}{l}\text { Diastolic BP, } \\
\text { mm Hg }\end{array}$ & $60.9(14.1)$ & $60.9(11.7)$ & 0.98 \\
$\begin{array}{l}\text { Pre-existing } \\
\text { micro-albuminuria }\end{array}$ & $10(38.5 \%)$ & $26(19.1 \%)$ & $0.030^{*}$ \\
$\begin{array}{l}\text { Gestational } \\
\text { diabetes }\end{array}$ & $10(35.7 \%)$ & $14(10 \%)$ & $<0.001^{* *}$ \\
\hline *p<0.05; **p<0.001. & & & \\
\hline
\end{tabular}

were $22.4 \mathrm{~kg} / \mathrm{m}^{2}(\mathrm{SD}=9.1)$ and $18.8 \mathrm{~kg} / \mathrm{m}^{2}(\mathrm{SD}=5.7)$ in cases and controls, respectively. The mean value of WC was $88.5 \mathrm{~cm}(\mathrm{SD}=19.1)$ in cases and $78.6 \mathrm{~cm}(\mathrm{SD}=15.7)$ in controls.

\section{Associations between anthropometric indices and GHD}

The ORs are presented in Table 3. All five anthropometric indices were positively associated with GHD (Table 3). The association between WC and GHD was statistically significant, with crude $\mathrm{OR}=1.8$ (95\% CI, 1.1-3.0). Furthermore, the association between BMI and GHD was also significant with crude OR $=1.7$ (95\% CI, 1.1-2.6). The associations of anthropometric indices with GHD in order of the magnitude of OR estimates were $\mathrm{WC}>\mathrm{BMI}>\mathrm{HC} \approx$
WHR $>$ WHtR (Table 3). Adjustment for age at pregnancy, alcohol drinking and cigarette smoking did not alter the order. The crude OR of high BMI for GHD was 2.8 (95\% CI, 1.2-6.7) and adjusted OR was 2.7 (95\% CI, 1.0-7.3).

\section{Discussion}

Our findings suggest that $\mathrm{WC}$, prior to pregnancy, is the best anthropometric predictor of GHD in Aboriginal women. All five indices are positively associated with GHD, and can be used to predict GHD several years prior to pregnancy. However, only the associations of BMI and WC with GHD are statistically significant, before and after adjusting for confounding factors. Moreover, women with high BMI before pregnancy have over twice the odds of experiencing GHD during pregnancy.

Although there are a number of studies have reported the impact of BMI, both before and during pregnancy, on GHD $[14,15,21]$, the associations of anthropometric measurements, other than BMI, several years before pregnancy with GHD have not been well reported. Aboriginal Australians are more likely to experience pregnancy related complications [22,23]; and they also tend to be obese in young adulthood [24]. Therefore, understanding the associations of GHD with different anthropometric measurements, prior to pregnancy, is potentially a useful method to identify high risk individuals [22]. This study is the first that assessed the associations of five anthropometric measurements prior to pregnancy with GHD, in Aboriginal women. Moreover, the data used in this study were obtained from a cohort with up to 20 years of follow-up, and the anthropometric measurements were undertaken several years (mean $=7$ years) prior to pregnancy. Therefore our findings could be valid evidence in terms of the impacts of WC and BMI several years prior to pregnancy on GHD.

Campbell et al. have also assessed the impact of WC and BMI before pregnancy on the development of gestational hypertension [13]. Their results, similar to ours, showed significant associations of WC and BMI with GHD. The current study is also comparable with a study

Table 3 Associations of different anthropometric measurements with gestational hypertensive disorders

\begin{tabular}{|c|c|c|c|c|c|c|}
\hline & \multicolumn{3}{|c|}{ Crude } & \multicolumn{3}{|c|}{ Adjusted $^{* *}$} \\
\hline & $\mathrm{OR}^{*}$ & $95 \% \mathrm{Cl}$ & $P$-value & $\mathrm{OR}^{*}$ & $95 \% \mathrm{Cl}$ & P-value \\
\hline$\overline{B M I}$ & 1.69 & $1.11,2.57$ & $0.014 * * *$ & 1.68 & $1.10,2.58$ & $0.016^{* * * *}$ \\
\hline Waist circumference & 1.82 & $1.12,2.95$ & $0.014 * * *$ & 1.78 & $1.10,2.89$ & $0.019^{* * *}$ \\
\hline Hip circumference & 1.60 & $0.99,2.57$ & 0.053 & 1.53 & $0.96,2.52$ & 0.068 \\
\hline Waist-to-hip ratio & 1.57 & $0.97,10.4$ & 0.056 & 1.65 & $0.80,3.39$ & 0.174 \\
\hline Waist-to-height ratio & 1.43 & $0.84,2.46$ & 0.186 & 1.44 & $0.83,2.51$ & 0.192 \\
\hline
\end{tabular}

*Odds ratios corresponding to one standard-deviation increase in BMI, waist circumference, and waist-to-hip ratio. Sample size varies by the associations, because of the missing information of anthropometric indices.

**Adjusting for age at pregnancy, alcohol drinking and cigarette smoking.

*** $p<0.05$. 
undertaken by Lake et al. In their study, the impact of BMI before pregnancy on development of GHD was determined among women who became pregnant by the age of 33 [25]. In that study, BMI measurements were carried out twice, at seven and 23 years of age. Their results showed a positive association between obesity at the age of seven and GHD. Lake et al. also reported a positive association between obesity at the age of 23, among women who experienced pregnancy by the age of 33 , and GHD, independent of their BMI at the age of seven [25].

Ijuin et al. have investigated the association between upper/lower-half-body ratio (body-fat amount ratio) and pre-eclampsia. Their findings could be comparable with ours in regard to association between WHR and GHD. According to their study, upper/lower-half-body ratio is associated with pre-eclampsia [26]. Both studies showed a positive association and a very large unadjusted point estimate. However, our findings did not show a significant association between WHR and GHD after adjusting for confounding factors. Furthermore, their results showed a weak association between BMI and pre-eclampsia, whereas a number of studies including ours showed a strong association even after adjusting for other risk factors.

In this study all participants were from a relatively homogenous Aboriginal community, which simplified the comparison between cases and controls, although there are no standardised BMI or WC cut-off points for this population.

One of the limitations of this study was its small sample size. In addition, because the number of missing data for some of the measurements (e.g. WHR, WHtR) was higher than the number of missing BMI data, the related assessments had a smaller sample-size than the original study groups, which reduced the related statistical power. In addition, because women with GHD in this study were identified through hospital records, minor GHD cases might had not been hospitalised, and misclassified as controls, which could have diluted the true associations between the anthropometric indices and GHD. There is also a possibility of human error in performing the anthropometric measurements. Since this study was conducted in one remote community, the generalisability of our findings to other Aboriginal communities remains to be verified.

\section{Conclusions}

There are positive associations between GHD in Australian Aboriginal women and their BMI and WC status several years prior to pregnancy. The findings of this study could have multiple clinical and public health implications. It is useful for clinical practitioners and the general public to understand the long term risk of high BMI and WC on GHD. In order to reduce the risk of GHD developing in Aboriginal women, it is important to prevent high BMI in children and young adults.
Competing interests

The authors declare they have no competing interests.

\section{Authors' contributions}

The contributions of each author in this work are as follows: MS drafted the manuscript and performed data analysis. MS, WH, ZW contributed to study design. WH and ZW obtained the data and provided guidance for data analysis and interpretation. All authors critically reviewed, revised and approved the final draft of the manuscript.

\section{Acknowledgements}

This study was financially supported by grants from NHMRC: APP1025350, APP1042343 (ZW) and \#511081 (WH). We especially thank the Aboriginal people who participated in this study. The baseline data were collected by the renal research team led by WH at the Menzies School of Health Research, Darwin, Australia. Shuqin Li at the Northern Territory Department of Health assisted in the interpretation of hospital data.

Received: 14 June 2013 Accepted: 25 February 2014

Published: 5 March 2014

\section{References}

1. Kumanyika S: Obesity in black women. Epidemio/ Rev 1987, 9:31-50.

2. Cunningham J, Mackerras D: Overweight and obesity, indigenous Australians. ABS cat. In . Canberra: Australian Bureau of Statistics; 1994. ISBN 0642232741.

3. Dawson D: Ethnic differences in female overweight: data from the 1985 national health interview survey. Am J Public Health 1985, 1988(78):1326-1330.

4. Kondalsamy-Chennakesavan S, Hoy WE, Wang Z, Briganti E, Polkinghorne K, Chadban S, Shaw J, AusDiab Study G: Anthropometric measurements of Australian aboriginal adults living in remote areas: comparison with nationally representative findings. Am J Hum Biol 2008, 20:317-324.

5. Lean M, Han T: Waist worries. Am J Clin Nutr 2002, 76:699-700.

6. Snijder M, Dekker J, Visser M, Bouter L, Stehouwer C, Kostense P, Yudkin J, Heine R, Nijpels G, Seidell J: Associations of hip and thigh circumferences independent of waist circumference with the incidence of type 2 diabetes: the hoorn study. Am J Clin Nutr 2003, 77:1192-1197.

7. Wang Z, Hoy W: Waist circumference, body mass index, hip circumference and waist-to-hip ratio as predictors of cardiovascular disease in aboriginal people. Eur J Clin Nutr 2004, 58:888-893.

8. Norgan NG: Interpretation of low body mass indices: Australian aborigines. Am J Phys Anthropol 1994, 94:229-237.

9. Lykke JA, Langhoff-Roos J, Sibai BM, Funai EF, Triche EW, Paidas MJ: Hypertensive pregnancy disorders and subsequent cardiovascular morbidity and type 2 diabetes mellitus in the mother. Hypertension 2009, 53:944-951.

10. Roberts JM, Redman CW: Pre-eclampsia: more than pregnancy induced hypertension. Lancet 1993, 341:1447-1451.

11. Chhabra S, Kakani A: Maternal mortality due to eclamptic and non-eclamptic hypertensive disorders: a challenge. J Obstet Gynaecol 2007, 27:25-29.

12. Panaretto $K$, Lee $H$, Mitchell M, Larkins S, Manessis V, Buettner P, Watson D: Risk factors for preterm, low birth weight and small for gestational age birth in urban aboriginal and torres strait islander women in Townsville. Aust N Z J Public Health 2006, 30:163-170.

13. Campbell SK, Lynch J, Esterman A, McDermott R: Pre-pregnancy predictors of hypertension in pregnancy among Aboriginal and Torres Strait Islander women in north Queensland, Australia; a prospective cohort study. BMC Public Health 2013, 13:138-138.

14. Callaway LK, Prins JB, Chang AM, Mclntyre HD: The prevalence and impact of overweight and obesity in an Australian obstetric population. Med J Aust 2006, 184:56-59.

15. Dodd JM, Grivell RM, Nguyen A-M, Chan A, Robinson JS: Maternal and perinatal health outcomes by body mass index category. Aust N Z J Obstet Gynaecol 2011, 51:136-140.

16. Cole T, Bellizzi M, Flegal K, Dietz W: Establishing a standard definition for child overweight and obesity worldwide: international survey. $\mathrm{Br}$ Med J 2000, 320:1240-1243.

17. Sayers S, Boyle J: Indigenous perinatal and neonatal outcomes: a time for preventive strategiesjpc. J Paediatr Child Health 2010, 46:475-479.

18. Hoy W, McDonald SP: Albuminuria: marker or target in indigenous populations. Kidney Int Supp/ 2004, 66:S25-S31. 
19. Chen JS, Roberts CL, Simpson JM, Ford JB: Prevalence of pre-eclampsia, pregnancy hypertension and gestational diabetes in population-based data: impact of different ascertainment methods on outcomes. Aust N Z J Obstet Gynaecol 2012, 52:91-95.

20. StataCorp: Stata statistical software: Release 12. In College Station: Texas: Stata Corporation; 2011.

21. Sibai BM, Gordon T, Thom E, Caritis SN, Klebanoff M, McNellis D, Paul RH: Risk factors for preeclampsia in healthy nulliparous women: a prospective multicenter study. Am J Obstet Gynecol 1995, 172:642-648.

22. Australian Indigenous Health Infonet: Birth and pregnancy outcome. In Canberra: Health Infonet; 2011. Available on: http://www.healthinfonet.ecu. edu.au/health-facts/overviews/births-and-pregnancy-outcome.

23. Hancock H: Low birth weight in Aboriginal babies-a need for rethinking Aboriginal women's pregnancies and birthing. Women Birth 2007, 20:77-80.

24. Sanigorski AM, Bell AC, Kremer PJ, Swinburn BA: High childhood obesity in an Australian population. Obesity 2007, 15:1908-1912.

25. Lake JK, Power C, Cole T: Women's reproductive health: the role of body mass index in early and adult life. Int J Obes 1997, 21:432-438.

26. Ijuin H, Douchi T, Nakamura S, Oki T, Yamamoto S, Nagata Y: Possible association of body-fat distribution with preeclampsia. J Obstet Gynaecol Res 1997, 23:45-49.

doi:10.1186/1756-0500-7-122

Cite this article as: Sina et al.: Anthropometric predictors of gestational hypertensive disorders in a remote aboriginal community: a nested case-control study. BMC Research Notes 2014 7:122

\section{Submit your next manuscript to BioMed Central and take full advantage of:}

- Convenient online submission

- Thorough peer review

- No space constraints or color figure charges

- Immediate publication on acceptance

- Inclusion in PubMed, CAS, Scopus and Google Scholar

- Research which is freely available for redistribution 